\title{
A modo de introducción: Cruzando puentes
}

Latinoamérica ha tenido una marcada presencia a lo largo de la obra de Manuel Vázquez Montalbán, como realidad histórica, escenario real e imaginario de insurgencias y represiones, así como metáfora de las asimétricas relaciones Norte/Sur. La educación sentimental y política de Vázquez Montalbán está impregnada a su vez de referencias latinoamericanas, desde la revolución cubana, los boleros de Antonio Machín o Chavela Vargas, los tangos de Carlos Gardel o Cecilia Rossetto, o el movimiento neozapatista. La obra de Vázquez Montalbán ha tenido asimismo una notable importancia como referencia en el pensamiento crítico latinoamericano, y una decisiva influencia en el desarrollo de la narrativa neopolicial. En conjunto, la obra de MVM abre amplias perspectivas transatlánticas que desbordan las fronteras tradicionales tanto nacionales como genéricas. El presente número monográfico de la revista se interesa en cruzar puentes y ahondar en estas perspectivas críticas.

En su ensayo "La reflexión sobre Latinoamérica de Manuel Vázquez Montalbán en la prensa (1989-2003). Pensamiento único, disidencia y globalización", Francesc Salgado sintetiza las preocupaciones periodísticas de Vázquez Montalbán en sus últimos años sobre la cambiante posición socio-política y económica de América Latina en un mundo radicalmente transformado por el colapso del bloque soviético y la aparición de un supuesto New World Order caracterizado por la globalización triunfal del neoliberalismo económico y la democracia política estadounidenses. En este contexto Salgado detalla la aguda crítica por parte de Vázquez Montalbán de la estrecha colaboración entre las dictaduras del Cono Sur y Centroamérica y sus asesores militares y económicos estadounidenses en encubrir la extrema violencia y desigualdad al fondo de su afamada transición a la democracia política y sus elogiadas reformas económicas. En cuanto a la nueva y difícil situación postsoviética de Cuba, Salgado nos recuerda cómo Vázquez Montalbán difirió de otros comentaristas políticos al distinguir claramente la gran diferencia entre la resistencia de la Revolución Cubana y los regímenes socialistas de Europa Oriental que cayeron con la URSS: la continua y cercana amenaza de los EEUU y la comunidad cubana contrarrevolucionaria exiliada de Miami. Frente a este peligro real a la soberanía y autodeterminación cubanas, Salgado señala cómo Vázquez Montalbán planteó la necesidad de una solución socialista interna en diálogo con los disidentes cubanos, mediado por políticos de izquierda europeos solidarios. En su discusión del entusiasmo de Vázquez Montalbán por la revolución zapatista, Sal- 
gado señala que para el autor esta fascinación no radica principalmente en su índole indigenista o antropológica, sino que se vincula al aspecto posmoderno de hacer revolución en un mundo globalizado utilizando las nuevas tecnologías, el activismo social, el espectáculo y la solidaridad internacional - es decir, reimaginar los medios comunicativos de la globalización y el neoliberalismo como armas de lucha contra-hegemónicas y utópicas.

En su contribución a este volumen, "Los movimientos indígenas y la globalización en los reportajes de Manuel Vázquez Montalbán”, Weselina Gacinska parte de una rigorosa investigación histórica y antropológica de la solidaridad política de Vázquez Montalbán con dos movimientos indígenas conocidos por sus líderes carismáticos y su lucha por la autodeterminación política y la justicia social en la era de la globalización, la expansión de los medios comunicativos y el neoliberalismo económico. En su discusión del compromiso personal de Vázquez Montalbán con la insurrección zapatista, Gacinska arraiga su análisis en la historia de la marginalización de la agencia indígena por parte del indigenismo oficialista de la Revolución Mexicana y sus políticas culturales y sociales de mestizaje. Gacinska indica como esta invisibilización gubernamental de las comunidades indígenas mexicanas atraviesa la romántica y bárbara visión occidental del indígena que Vázquez Montalbán criticaba irónicamente en el cine western cásico estadounidense de John Ford. Gacinska muestra cómo Vázquez Montalbán rompió con estas visiones abstractas y despectivas de los movimientos sociales indígenas y defendió entusiastamente a Marcos como portavoz y a los zapatistas como un nuevo modelo sincrético de izquierda y lucha social. En cambio, en la controversia sobre la política identitaria y el polémico debate sobre la diferencia entre memoria e historia en el testimonio de la activista indígena guatemalteca y Premio Nobel de la Paz Rigoberta Menchú, Me llamo Rigoberta Menchú y así me nació la conciencia (1983), Gacinska relata cómo Vázquez Montalbán dejó de lado las críticas y observaciones de antropólogos occidentales sobre la heterogeneidad política de las comunidades indígenas de Guatemala y apreció a Menchú como una representante directa de su pueblo sin necesidad de portavoz que hable por ella ni antropólogo que avale la verdad de sus reclamaciones comunitarias.

En su ensayo titulado "El espejo empañado: $Y$ Dios entró en La Habana, entre reportaje literario y remodelación autoficcional", Albrecht Buschmann abarca con gran lucidez analítica y destreza textual el complicado relato de viaje transatlántico, análisis político y testimonio auto- 
biográfico, Y Dios entró en la Habana, que Vázquez Montalbán escribió después de su visita a Cuba para informar sobre el viaje del papa Juan Pablo II a la isla en 1998 para la prensa española. En su investigación de este libro rico en relaciones intertextuales con otros textos montalbanianos de género híbrido, Buschmann demuestra un gran manejo de la historia de las ideas literarias, sociológicas y políticas en juego a través de una larga series de textos, autores y contextos nacionales a la vez diferentes e interrelacionados. Buschmann hace particularmente evidente la complejidad de este libro que en parte constituye un ensayo sobre la crisis del socialismo cubano y global al fin del milenio a la vez que señala el conflicto entre la izquierda (o derecha) posmoderna y el realismo socialista tradicional. A este respecto, Buschmann destaca el aspecto discursivamente heterogéneo del texto, es decir, su palimpsesto de características ensayísticas, testimoniales y autorreferenciales, las cuales complican la relación entre Manuel Vázquez Montalbán como figura narrativa y política, el propio Vázquez Montalbán y sus múltiples interlocutores.

La noción de educación sentimental ha acompañado la obra y el pensamiento de Vázquez Montalbán desde sus comienzos, ya desde su primer poemario titulado precisamente Una educación sentimental (1967), pasando por sus célebres Crónica sentimental de España (1969/1971) y Crónica sentimental de la transición (1985). La propuesta innovadora de Vázquez Montalbán era un ejercicio de recuperación crítica de la memoria individual y colectiva en los años del franquismo, de la exploración de los sentimientos y la construcción de una identidad cultural, y de su expresión en la cultura popular de masas, como el cine, la música o el fútbol.

La huella latinoamericana en la educación sentimental del autor y en su obra es omnipresente. Marina Castrillo y Wadda C. Ríos-Font exploran diversos aspectos de dicha educación sentimental en sus colaboraciones para este número. En su ensayo "Acordes Transatlánticos: Vázquez Montalbán y el tango como educación sentimental y política" Marina Castrillo se adentra en una exploración del papel del tango en la educación, no solo sentimental sino también política, del autor. Castrillo rastrea con gran habilidad la geografía emocional del tango y su importante huella a lo largo de la variada obra del autor, rescatando significativos y recurrentes rastros en sus poemas, ensayos, reseñas, e incluso sus propios tangos, y deteniéndose en particular en el tándem de novelas "argentinas" La muchacha que pudo ser Emmanuelle y Quinteto de Buenos Aires (ambas de 1997), las cuales no habían sido analizadas conjun- 
tamente con anterioridad, y que desde ahora será ineludible considerar. A través del análisis de estos acordes transatlánticos, enfocándose en el aspecto emocional, cultural y político que conllevan los tangos, Castrillo realiza una sugestiva lectura de las transiciones políticas en España y Argentina que revela historias compartidas de silencios, desapariciones y traumas, pero también lazos de afinidad, memoria, solidaridad y resistencia. El artículo contiene como apéndice un inédito escrito de la intérprete de tangos Cecilia Rossetto sobre Vázquez Montalbán, en el que se explaya sobre su misteriosa desaparición de la edición argentina de Quinteto, en una novela llena de misterios, silencios, traumas, olvidos y desaparecidos.

Por el papel central de los sentimientos en la obra de Vázquez Montalbán, como hemos mencionado anteriormente, esta se presta idealmente a una lectura crítica desde la perspectiva de la teoría de los afectos. Esto es precisamente lo que realiza Wadda C. Ríos-Font en su ensayo "Quinteto de Buenos Aires: La educación sentimental de Pepe Carvalho". Su innovadora propuesta ofrece una lectura atenta, detallada y rigurosa de la novela Quinteto en Buenos Aires y de los mecanismos afectivos del personaje de Pepe Carvalho. La autora propone que apartándose de la racionalidad característica del género policiaco, y apostando por la fragmentación, la duplicidad y reduplicación, en lugar de la linealidad narrativa, Vázquez Montalbán lleva a Carvalho por un territorio emocional, que no persigue simplemente la esclaración de la verdad o la justicia sino encontrar zonas de solidaridad y resistencia. Siguiendo los postulados de Monique Scheer y Walter Reddy sobre la regulación de los afectos en regímenes represivos, la autora sugiere que la novela busca provocar una "subversión emocional" de los regímenes dictatoriales español y argentino, así como de los regímenes neoliberales que engendraron, y por medio de la liberación de los mecanismos afectivos, contribuir asimismo a una forma de catarsis emocional ante la violencia física, económica y política. Formas de sentimentalidad como la ternura, la complicidad y la solidaridad se convierten así en formas activas de resistencia.

El viaje es un elemento característico de la saga de Pepe Carvalho, personaje que se siente profundamente desplazado y desorientado por los efectos del neoliberalismo, y se manifiesta igualmente a lo largo de la obra narrativa, poética y ensayística de Vázquez Montalbán, como una respuesta a la frustración de la modernidad, siempre sentimental y filosóficamente en busca de "ese lugar del que no quisiera regresar", pero también políticamente en busca de respuestas y alternativas al agota- 
miento de la izquierda. Williams Nichols completa el trío de estudios que analizan diversos aspectos de Quinteto en Buenos Aires en este número monográfico, desde una perspectiva crítica diferente. En su ensayo titulado "Viajes al futuro y sociedad del simulacro: Modernidad, Disneyficación y ruinas de la resistencia en Quinteto de Buenos Aires de Manuel Vázquez Montalbán”, Nichols enfoca su análisis desde las teorías de los estudios de viajes, la globalización y el simulacro. Basándose sólidamente en los estudios del turismo de Dean MacCannell, John Urry, Claudio Minca y Tim Oakes, entre otros, Nichols plantea el motivo del viaje entendido como metáfora de la globalización, de sus contradicciones y asimetrías, así como de la memoria como forma de estrategia de resistencia frente a los procesos de disneyficación en la sociedad del simulacro. Nichols sostiene que el viaje en Quinteto de Buenos Aires funciona como una forma de afirmación de la agencia individual y búsqueda de autenticidad frente a la parque-tematización de la sociedad contemporánea teorizada por Michael Sorkin y a la incertidumbre existencial de la sociedad del simulacro.

Este número monográfico se completa con el ensayo de José Colmeiro, "Libros como puentes: Bibliografía latinoamericana de Manuel Vázquez Montalbán. Archivo en construcción", que presenta un amplio compendio, comprehensivo pero inevitablemente incompleto, de la bibliografía del autor sobre Latinoamérica y de la crítica, tanto académica como periodística, sobre la misma. Este archivo en construcción revela en primer lugar la enorme dedicación de Vázquez Montalbán a Latinoamérica a lo largo de los años, especialmente notable en su obra como ensayista, periodista y novelista, algo que la crítica apenas ha percibido hasta el momento en su más amplia dimensión. Por otra parte, se hace más evidente aun la palpable falta de estudios de conjunto sobre la importante relación de Vázquez Montalbán con Latinoamérica, que este número monográfico intenta corregir, y allana el camino para futuros trabajos de investigación que ahonden en esta temática y que esperamos vean la luz en los próximos años.

Michael Aronna y José Colmeiro 